ISSN: 2162-3104 Print/ ISSN: 2166-3750 Online

Volume 6, Issue 1 (2016), pp. 128-152

(C) Journal of International Students

http://jistudents.org/

\title{
International Female Graduate Students' Experience at a Midwestern University: Sense of Belonging and Identity Development
}

\author{
Anh T. Le \\ University of Nebraska-Lincoln (USA) \\ Barbara Y. LaCost \\ University of Nebraska-Lincoln (USA) \\ Michael Wismer \\ University of Nebraska-Lincoln (USA)
}

\begin{abstract}
International female graduate students have to negotiate multiple aspects of their identities as non-native learners and women in a society with different gender norms than their home countries. However, their experiences have not been well researched within the scholarship on international students. In this study, using the phenomenological approach, we explored the phenomenon of being an international female graduate student in the U.S. The seven participants are diverse in terms of countries of origin, academic programs, and life situations. Using open-ended questions, we conducted indepth one-on-one interviews with the participants. The findings indicate that the participants perceived being international female graduate students at this university as a positive, life-changing, and transformative experience.
\end{abstract}

Keywords: international students, sense of belonging, identity development, graduate students, female students

In recent years, international collaboration and cooperation have become a major national trend in the higher education sector. In the 2012-2013 academic year, according to the Open Doors report (IIE, 2013), the total number of newly enrolled international students in the U.S. was 250,920. 
The total enrollment of international students in U.S. institutions in 2013 was at a record high of 819,644 students. According to the Institute of International Education's Special Reports: Economic Impact of International Students, in the academic year 2013-2014, international students contributed over $\$ 27$ billion to the U.S. economy through their expenditures on tuition and living expenses (IIE, 2015). Higher education is among the United States' top service sector exports, as international students provide revenue to the U.S. economy and individual host states through expenditures on living expenses, including room and board, books and supplies, transportation, health insurance, support for accompanying family members, and other miscellaneous items. Open Doors (IIE, 2013) also reports that in academic year 2012-2013, approximately $63.60 \%$ of all international students received the majority of their funds from personal and family sources.

These numbers represent the promising economic value potential of the international education field. However, they also represent a new learning curve for U.S. educators needing to design and improve services for international students since many international students experience cultural, social, and linguistic challenges that are different from those of domestic students (Arkousdis, 2006). More specifically, female international students have been found to have more difficulty in adjusting to host cultures than male students (Manese, Sedlacek, \& Leong, 1984; McMillen, 1982; Pruitt, 1978). Being in a graduate program of study also has its own challenges as graduate students have to constantly navigate a host of different stressors, such as financial issues and getting used to the norms of their academic fields (Baird, 1990). Thus, international female graduate students have to maneuver the combined difficulties of being international, female, and graduate students at the same time, all while trying to achieve academic and social integration into the U.S. academic environment and society.

The purpose of the current phenomenological study was to explore international female graduate students' experiences at a U.S. research intensive, comprehensive, predominantly white university in the Midwest. The central question of this research study is, How do the participants perceive and interpret their lived experience as international female graduate students at this particular Midwestern university?

\section{RELEVANT LITERATURE}

While all students entering higher education have to cope with the myriad new facets of the educational environment, the majority of international students have to deal with additional challenges, such as language and culture gaps (Bradley, 2000; Ellis, Sawyer, Gill, Medlin, \& Wilson, 2005). 
Similar to domestic students, international students are at risk for developing mental health problems, but international students are at higher risk due to loss of social support and family systems and to acculturation stress (McLachlan \& Justice, 2009). Mental health problems, such as depression, psychosomatic complaints, anxiety, and paranoid reactions, have been suggested to be more common among international students (Sam, 2001).

The additional difficulties faced by international students contribute to their mental health risks. These include language difficulties, cultural shock, difficulties in negotiating day-to-day social activities, racial and ethnic discrimination (Lee \& Rice, 2007; Lee, 2007, 2008; Li, Fox, \& Almarza, 2007; Sam, 2001; Wang, 2009; Zhao, Kuh, \& Carini, 2005), and a lack of physical activity (Yoh, Yang, \& Gordon, 2008). The literature on international students has identified several major problems common to this population, such as loneliness, lack of support, few meaningful relationships with host nationals, culture shock, unfamiliar modes of teaching and learning, a changing sense of identity, unrealistic family and selfexpectations, financial problems, crises at home, adverse experience in the host country, isolation, and alienation (Deakins, 2009; Hanassab, 2006; Klomegah, 2006; Leask, 2009; McClure, 2007; Mitchell, Greenwood, \& Guglielmi, 2007). Furthermore, when international students, especially doctoral students, return home, they can sometimes find themselves feeling frustrated because of the vast differences between their overseas doctoral training and the realities of their home countries (Robinson-Pant, 2009).

More specifically, a qualitative study based on in-depth interviews with twenty-two Asian students at a New Zealand tertiary institution provided a critical summary of important challenges: (a) language difficulties and cultural differences, (b) unfamiliar patterns of classroom interactions, (c) lack of knowledge of academic norms and conventions, (d) inadequate learning support, (e) difficulties in making friends with domestic students, and (f) lack of sense of belonging (Campbell \& $\mathrm{Li}, 2008$ ). Similarly, in a study of 200 international students in Australian universities, Sawir, Marginson, Deumert, Nyland, and Ramia (2008) found that twothirds of the group had experienced problems of loneliness and/or isolation, especially in the early months. Lee and Rice (2007) addressed international student perceptions of discrimination in the U.S. Based on in-depth interviews with 24 students from 15 countries, the authors considered the numerous difficulties the students encountered, which ranged from perceptions of unfairness and inhospitality to cultural intolerance and confrontation. Some participants in the study reported that Americans' lack of desire to understand another culture contributed to their feelings of cultural alienation. Some participants even experienced direct abuse that involved verbal insults, which left deep impressions that these students 
could not easily forget. Lastly, Urias and Yeakey (2009) conducted an analysis of the U.S. student visa system that emphasized its misperceptions, barriers, and consequences. The researchers concluded that international students and scholars, especially those from the Middle East, experienced frustration and anxiety when first entering the US. Going through the regulatory maze proved to be yet another daunting challenge for international students in the U.S.

Given the complex host of challenges they face, international students' adjustment to their new lives overseas can be a dynamic and multifaceted process (Brown \& Holloway, 2008). In an ethnographic study of international postgraduate students at a university in the south of England, Brown and Holloway (2008) found an association between the passage of time and a gradual decrease in acculturative stress. However, this was not a generalizable process; there was fluctuation not only in experiences across the student body but also in the individuals' subjective sense of success across different aspects of life in the new country. Additionally, in a study of 124 Turkish students studying in the U.S., Bektas, Demir, \& Bowden (2009) found that social support and self-esteem were predictors of psychological adjustment. Also, the results revealed that separation - co-national relationships - was the typical attitude of the participants in terms of their acculturation. Wang (2009) introduced the concept of resilience into the study of adjustment of international graduate students at U.S. universities. He explored relationships among resilience characteristics, background variables, and adjustment problem areas, and the effects of resilience and background variables on adjustment. The study's statistical analyses revealed that resilience characteristics were moderately associated with background variables, correlated negatively with adjustment problem areas, and were better correlated with adjustment problem areas than were background variables. These correlations suggested that resilience had the greatest association with adjustment.

In addition to the stressors of being international students, being a female further compounds the challenges, as female international students have been found to have more difficulty in adjusting to host cultures than have male students (Manese, Sedlacek, \& Leong, 1984; McMillen, 1982; Pruitt, 1978). In a more recent study about identity negotiation among female Chinese international students at a U.S. Midwestern public university, Hsieh (2006) posited that most of the participants had difficulty in negotiating a positive social identity because the dominant society tended to view their emphasis on interpersonal harmony as being submissive and a sign of incompetence. Female Chinese international students, Hsieh argued, tend to embrace the passive and yielding female role of the Confucian philosophy. Thus, Hsieh's participants' cultural background was an 
additional constraint on their identity development. Additionally, in a study about social support for graduate international students, Mallinckrodt \& Leong (1992) found that female international graduate students generally reported more problems socially, psychologically, and educationally than did their male counterparts. They also found that female graduate students reported having less support from their academic departments and families than did their male counterparts. Unfortunately, not much attention has been focused on the specific challenges and positive aspects of being an international female graduate student.

Lastly, being a graduate student also comes with certain challenges. Just like a freshman transitioning from high school to college, many firstyear graduate students find it stressful and overwhelming to transition from undergraduate to graduate programs. Many challenges are associated with graduate education. Baird (1990) argued that graduate students have to constantly navigate a host of different stressors, such as financial issues and getting used to the norms of their academic fields. Also, as they move into the graduate program, they have to start looking for friend groups, the right faculty advisor, and the right professional connections. In addition to the typical challenges faced by graduate students, international graduate students also experience linguistic, cultural, and instructional and academic challenges (Lin and Scherz, 2014).

The compounded stressors and challenges of being an international, a female, and a graduate student call for researchers and educators to pay more attention to the experiences of these students. This study aims to explore the experiences of international female graduate students at a research intensive university. The findings of this study will serve as a helpful resource for higher education professionals and faculty looking to better understand the international female graduate student population and to be better equipped to help these students. Administrators can also draw information from this study to inform their policy making decisions.

\section{METHOD}

To explore the experience of international female graduate students at a Midwestern university, we adopted the qualitative approach, which seeks to explore questions about how experiences are created and given meaning to (Bogdan \& Biklen, 1992). More specifically, the phenomenological approach was employed because we wanted to explore "the common meaning of several individuals of their lived experiences of a concept or a phenomenon" (Cresswell, 2012, p.76). The phenomenological approach encourages in-depth reflection from the participants and allows the researchers to gain deeper insights into their experiences (Lester, 1999). 
Additionally, the interpretive nature of the phenomenological approach supports the development of an emerging framework through the analysis of the participants' responses (Smith, Flowers, and Larkin, 2009).

To address the central research question - "How do the participants perceive and interpret their lived experience as international female graduate students at this particular Midwestern university?” - we conducted in-depth interviews with international female graduate students. We used a list of open ended interview questions to gather information about each individual participant's experiences such as how do you describe your experience as an international female graduate student at a Midwestern university?

\section{Data Collection}

We used a purposive sampling strategy to select participants for this study. We contacted an international student group on Facebook to ask for participation. A recruiting message was sent to the group's Facebook message box and asked the page administrators to forward the message to all group members. The message described in detail the purpose and the significance of the study, the criteria for participants, and what participants would be requested to do. A document of informed consent was attached to the message for review. Our contact information was included in the message so that interested individual could contact us directly. Seven students who met the criteria agreed to participate in the study. We conducted in-depth interviews with each participant about their experiences. Prior to the interviews, we emailed the participants the interview questions so that they could review the questions and reflect upon their experiences before the interview. The interview durations range from twenty-five to forty-five minutes. Each interview was audio recorded with the participant's permission. The interviewers also took notes during the interviews.

\section{Participants}

The participants were seven international female graduate students whose assigned pseudonyms are Linda, Cindy, Kim, Annie, Beth, Sam, and Jane. Their living situations are diverse. Linda is married with a young baby. She and her husband are both graduate students at the university. Cindy is also married. Her husband lives back in her home town, so she is living by herself in the U.S. Kim is married and lives with her husband in town. She also has her family living nearby. Beth is also married and living with her husband, who is also a graduate student at the same university. Jane, Sam, and Annie are single, each living with a roommate. The participants' demographic information, including country of origin, academic major, age, and length of stay, are presented in Table 1. 
Table 1:Participants’ demographic information

\begin{tabular}{|c|c|c|c|c|}
\hline Name & $\begin{array}{l}\text { Country of } \\
\text { Origin }\end{array}$ & Major & Age & $\begin{array}{l}\text { Length of } \\
\text { stay (years) }\end{array}$ \\
\hline Linda & China & $\begin{array}{l}\text { Educational } \\
\text { Psychology }\end{array}$ & 31 & 3 \\
\hline Cindy & China & $\begin{array}{l}\text { Educational } \\
\text { Psychology }\end{array}$ & 31 & 3 \\
\hline Kim & Ukraine & $\begin{array}{l}\text { Educational } \\
\text { Administration }\end{array}$ & 30 & 4 \\
\hline Annie & China & Business & 29 & 2 \\
\hline Beth & Iran & Engineering & 28 & 3 \\
\hline Sam & Iran & Engineering & 26 & 2 \\
\hline Jane & Kyrgyzstan & Architecture & 29 & 5 \\
\hline
\end{tabular}

\section{Data analysis}

The audio records of the interviews were transcribed by the researchers. We also reviewed the notes taken during the interviews to add more data. While reading the transcripts, we highlighted key concepts and wrote notes in the margins to record initial thoughts and ideas for analyzing the text. The transcribed text was coded independently by each of the researchers. Descriptive coding was used to generate a set of codes that are words or phrases that seem to stand out as significant or summative of what was being said. The coding was discussed and agreed upon by all the researchers. Next, codes were grouped into categories, which in turn were integrated into major themes using a computer-assisted qualitative data analysis software called MAXQDA. The codes were listed in the order they appeared and then were clustered into categories based upon similarities. These categories were then further grouped into major themes. We then wrote a description of what the participants in the study experienced as an international female graduate student at a Midwestern university. Finally, adhering to phenomenological research approach traditions, we wrote a structural description of how the experience happened and a composite description of the essence of the experience.

We employed three methods of verification to demonstrate the validity of the analysis: (a) peer review, (b) clarifying researcher bias, and (c) member checking. Specifically, we asked colleagues who have extensive experience in the conducting of qualitative studies to review the study. Also, 
we discussed in detail our backgrounds, international experiences, and potential biases that might influence the interpretation of the data. In addition, we invited the participants to review their respective transcripts to check for accuracy.

\section{Roles and Perspectives of the Researchers}

The researchers in this study perceive the world from divergent perspectives. The first researcher is a former female international graduate student from an Asian country. She had experienced many of the typical challenges facing international students such as a language barriers, loss of support systems, and cultural shock. However, she also had many positive experiences and life changing opportunities as a result of her time in the United States. Recently, she had a child and found that being a new mother without family support structures is very stressful. The challenge of childrearing without family support made the first researcher more conscious of her situation as an international female graduate student. The second and third researchers were born and raised within the dominant U.S. perspective. The second researcher is a female faculty member. In her role as a faculty member, she has taught and advised several international graduate students. The third researcher lived and worked abroad for two years, experienced the rigors of graduate school while far away from support structures, and worked in international student services. As a female international graduate student, developing a relationship through commonality was easier for the first researcher, whereas the second and third researchers used empathy and a sincere interest to relate to the participants.

\section{FINDINGS}

As outlined in the literature review section, much of the current literature relating to international students tends to highlight their challenges and barriers. Thus, at the beginning of the study, we expected that the participants would focus their reflections mainly on the difficulties in being international female graduate students. However, through data analysis, we found that they shared a positive perception of the study abroad experience. From the participants' reflections, four themes were discovered: (1) positive personal growth and development, (2) support network, (3) sense of belonging, and (4) appreciation/gratitude.

\section{Positive personal growth and development}

All of the participants emphasized their positive growth and development as a result of being an international student in the U.S. 
Looking back, they each were astounded by how much they had developed as a person. Before coming to the US, they all had lived with their parents, as was customary for women in their cultures. Upon arriving in the U.S., they were initially shocked by having to take on the responsibilities of arranging their own living situation. However, once they settled in, they felt proud of themselves for being able to live independently, as Jane shared:

I've developed as a person living independently. That's been, you know, a different experience for me because back home everybody lives with their families. It's totally different from here. And it was a big step for me to move out of my host family home and rent an apartment which I was responsible for finding.

In addition to learning how to take care of their own living situation, the participants also developed their confidence in social and academic situations. Some of them were amazed by how they had transformed from being so very shy to being able to socialize with diverse groups of people from all over the world. The participants' self-confidence and self-esteem were also enhanced through positive interactions with and encouraging comments from the people around them. Linda explained how her confidence had grown, "I worked hard, and my hard work was appreciated by the people around me. So I think that's how I become more confident." Similarly, Cindy shared that the "positive comments were very helpful" and helped her "to build the self-confidence and also self-esteem." As they overcame the initial shock of being in the new academic environment, they developed a sense of academic self-efficacy. They had been high achieving students back home. Thus, they experienced tremendous stress when they first realized that they were struggling in their courses, but they persevered. Over time, they learned how to adapt to and thrive in their academic setting, as Sam recalled, "I learned how to learn, how to study for exams, how to do projects, how to contact instructors. It takes time.”

As their self-confidence grew, they became more involved with people and activities that further exposed them to more diverse perspectives, which ultimately helped them develop a more open-minded attitude and critical thinking skills. Exposure to diversity is one of the important variables affecting college students' cognitive development to a higher level of cognitive complexity (Knefelkamp, 1999). As most of the participants came from monocultural societies, coming to the U.S. presented them with their first real encounter with diversity in terms of cultures, ethnicities, and perspectives. The participants loved this aspect of their study abroad experience, as Kim reflected: 
I think it definitely broadens your perspective on the world, because I really appreciate the fact that, here, you have such a different mix of cultures, you meet people from different countries and different parts of the world. So, I think diversity is very important. And so I really like that aspect.

They were also being challenged in their courses to develop a different perspective on how to evaluate knowledge. Confronted with a vast amount of new knowledge which presented complex and often conflicting ideas, they realized the importance of being able to critically assess and evaluate new ideas. Reflecting back on her experience, Cindy talked about how she had learned to look at things differently, "after learning so many knowledge or the research that you find yourself look at things differently. For me, I have developed to be able to look at things more critically.”

In addition to the changes in their cognitive development, the participants also spoke to the changes in their psychosocial identity. Some researchers have argued that as international students face challenges in the new environments their identities might become fragmented, which leads to difficulties in constructing and presenting a positive sense of self or identity (Hsieh, 2006; Pollock \& Van Reken, 1999; Vertovec, 1999). However, the participants in this study described a more positive identity transformation which closely resembles the "third place identities" concept as explained by Kramsch (1993). Kramsch's (1993) notion of "third place identities" suggests a more positive view of the international student experience in which the students are able to become unencumbered by the social norms of a particular nationality, ethnicity, or culture and are more free to reconstruct a new identity that is more aligned with their inner values and their new experiences. This state of in-betweenness provides international students the ability to overcome the social pressure to conform to either home or host culture and to establish new hybrid forms of identity (Bhabha, 1994). One of the participants, Linda, expressed how she had become much more comfortable with herself, "I'm more comfortable with myself. I don't care too much about the things I cared so much when I was in China. Maybe that's part of growing up ... being more mature..." She thought she was just "becoming a better person." Another participant, Jane, spoke about how she was able to be more authentic to herself, "I feel that this environment is very natural to how I feel inside, how things should work, how my life is supposed to go." In terms of external influences on identity, Cindy felt that she was able to develop a more positive self-image since she has been in the U.S. because "people here gave me nice compliments about my looks. I am a size 0 or XS here. But when I went back home to visit, people kept saying that I am fat. They are very critical.” These participants had achieved more 
positive identities because the study abroad experience has enabled them to be aware of and successfully navigate the "ongoing negotiation between the individual and the social context or environment" that is the foundation of identity development (Hawkins, 2005).

\section{Support Networks}

Professors/Advisors. One of the biggest challenges for international students is the loss of support networks. The participants in this study experienced that loss too, but they have learned to create new support networks. Most of them mentioned their professors, especially major advisors, as being an important source of support. As graduate students, the participants were able to form a close relationship with their professors and advisors. They were impressed by their professors' subject expertise and openness toward helping students. As Jane noted, “All the professors that I take classes from I developed very good positive relationship with them, and I'm always impressed by their knowledge.” She also felt that her professors were excellent at making students feel welcome and supported:

The professors in our program are very friendly, and they spend so much time in their offices that it's never a problem to knock on their door and get their advice. And for that matter, even the program director . . . the way she communicates with her students tells you that the students are her main priority. They can come in at any time.

For all of the participants, their advisors were also their graduate assistantship supervisors. Thus, they were able to spend a great deal of time building positive relationships with their advisors. They were also able to rely on their advisors for support not only on academic matters but also in other aspects of their lives. When Linda gave birth to her first child while in the $\mathrm{PhD}$ program, she was grateful for advisor's support:

The greatest support I received is from my advisor, because he is my boss, my manager, and I'm supposed to report to him. He is being flexible over time.

But ever since I got pregnant, and I have the new baby, and he has been really flexible, and he didn't require me to stay in the office, like, at some exact times.

For the participants, the advisors' unofficial roles as mentors and role model were an important part of the participants' support network, as was 
demonstrated by Kim's assertion that her advisor "played a big role" in her support system and that she "could ask any question and not be ashamed of asking questions.”

Family. In addition to their professors/advisors and academic departments, local support networks including families, friends, and oncampus services were also mentioned as important supports for international students. For some of the participants, their familial support came from their host families, who welcomed them to the U.S. and helped them adjust to their new lives. Even after they moved out on their own, they still maintained strong connections with their host families. Having that sense of familial connection was instrumental in alleviating common challenges facing international students such as homesickness and loneliness, as reflected in Jane's comments about her host family:

I have a family here too. The same host family that hosted me for that summer. I feel very connected, and we are very close. We celebrate holidays together. We visit each other every once in a while. They're busy, I'm busy. But we have find . . . we find time to get together to catch up, and I never felt like I was lonely.

Some participants found that being in a new environment had made them more appreciative of their spouses' support. Together, they went through the hardships of adjusting to their new social and economic situations. Changes in gender role expectations and social norms were difficult for some of the spouses to understand and adjust to. However, at the time of the interview, the participants shared that they felt supported by their spouses, and together they were able to overcome challenges, to adapt to their new lives, and to thrive in their relationships. For these women, being in the new environment has given them and their spouses the space to define or redefine their roles and expectations in the marriage. The study abroad experience brought them closer to each other as partners because they depended heavily on each other to get through difficult times. As Beth reflected, "Without my husband, it [adapting to life in the US] would have been much harder."

Friends. A number of research articles on the patterns of international students' social networks suggest that their strongest connections are usually from conational networks (Bochner, McLeod, \& Lin, 1977; Pham \& Saltmarsh, 2013; Searle \& Ward, 1990; Ward \& Kennedy, 1993). However, the friendship patterns of the participants in this study presented a balanced mix of conational, international, and domestic 
student friends. Conational friends were particularly helpful during the initial adjustment period when they first arrived in the U.S. Over time, through their courses and social activities, they were able to make friends with other international students and with domestic students. They all had a core group of friends that they were close with and received support from. These core groups tended to consist of at least one or two conational friends and several international friends. Domestic friends tended to be "good friends" but not "close friends." The participants seemed to form strong connections with the friends that had been there to help them out during their hardest time, the first arrival period. They recalled vividly how grateful they had felt for the friends that helped them with practical issues such as transportation, temporary housing, banking, completing paperwork, etc. Sam provided a great example for how her friends had helped her at the beginning:

When I first arrived here a student from my home country gave me a ride from the airport, and got me to the first store that I went, which was Target. So I went there and I bought a pillow, and blankets and something to sleep on. Then I went to my friend's house and was able to stay there for a week until I rented my own apartment. I didn't even have a car for a year, so for shopping I went with friends.

Another participant, Kim, was also impressed with how helpful her fellow graduate students were to her when she first arrived and did not yet know how to navigate the campus:

I think my friends who are graduate students. Those were also very helpful, because they were already, like, finishing their programs or in the middle of their programs, so they knew a lot about [UNIVERSITY NAME] and, you know, what you needed to do. So that was very helpful, as well. I remember, like, when I only came here, I didn't know where I needed to go to do the, you know, bank [...] So those were helpful. And first times, they even went with me.

For Cindy, who was in a long distance relationship with her husband for the duration of her doctoral program, her friends were her only support system in the U.S. She shared that "the friendships were very nice. Otherwise I won't survive for the first three years to be honest." 
After the initial survival-focused period, the participants were able to extend their friendship networks through their graduate assistantships, course work, and friends, as Jane described:

Personally I've expanded my network in terms of people, you know, friends. I have great number of friends and I don't consider them just friends. People that I could call friends. They are friends that are really interested in what's going on in my life.

Thus, the idea of international students being isolated in their conational groups, so prevalent in the literature and popular discourse on international students, is not supported by the findings of this study. The participants in this study were actively creating both new conational and non-conational friendships as they progressed through their academic programs.

On-Campus Services. Besides family, the participants also received support from various offices on campus, such as the Student Health Center, Graduate Studies, and the International Students and Scholars Services Office. The staff in these offices were perceived to be warm, nice, and helpful, and the services were great. Though they rarely used on-campus services, as they perceived them as focusing mainly on undergraduate students' needs, when they did use the services, they found the services to be relevant and effective, as demonstrated by a comment from Kim:

I was definitely utilizing international affairs. I was going there because we're required to do different paperwork there. So those [activities hosted by International Affairs], I think, were nice. And I think graduate studies personnel was also very nice, and I asked a lot of questions for different forms and stuff. So I think those were very, very supportive services for me.

One participant, Sam, contrasted the quality of support services she was receiving on her current campus to what she had experienced back home:

I like the culture here. I like that people respect each other here and that they really listen to what you're saying and respect what you are saying. Campus services really pay attention to you and want to solve your problems. One of the very good experiences here is that you don't need to solve your problems by going places and talking to the people. You can contact them with email. By contacting someone with a phone you can solve a very big problem. This is 
something that I did not experience in my country; in my country everything is that you should go to that place and talk to those people for a couple of days, a couple of hours, and express yourself. Gather so many signatures and the like. Here it is not like that, one person can solve your problem very easily by phone or by email. And that is very nice.

On-campus services were perceived to be helpful and easily accessible in times of need for the participants. Though they mostly relied on their social networks for support, they did utilize some on-campus student support services as necessary. They expressed a general satisfaction with the quality of these services.

\section{Sense of Belonging}

All of the participants felt a sense of belonging to their new living environment. All of them came from countries where the cultural norms emphasized conformity and patriarchal gender roles. Thus, for these highly educated women, going to the U.S. was their chance to explore their true selves unencumbered by the rigid social norms of back home. Though they still followed the more traditional life patterns of heterosexual females, such as looking for serious relationships only, getting married, having children, and so forth, internally, they felt a sense of profound changes in their selfdetermination and self-fulfillment. They also felt that people here were more open-minded, relaxed, and welcoming to strangers. Most of them came from big metropolitan cities where competition and social pressure to conform was fierce, so they appreciated the new environment where they could have the freedom and mental and physical space to reflect on their identities. For example, Jane shared that her current environment "fits me like a glove" and that here she could feel free to "be who you feel you are, as opposed to trying to blend in." Thus, she felt that "this community and this environment, this lifestyle, fits me so well that I can't imagine living in any other environment."

Additionally, the hospitable local culture and atmosphere on campus helped the participants feel welcome and succeed academically. When they first arrived, they were very self-conscious about their deficits in language skills and cultural knowledge. However, as they progressed through their courses, they were encouraged by the academic environment to be more confident in their opinions, as demonstrated by Annie's reflection that her transition took a long time but that the "freedom and friendly class atmosphere impressed me and let me believe my international opinions were valuable. As time went on, I felt more comfortable to participate and speak in class day by day.” 
Another aspect of the new environment that contributed to the participants' sense of belonging was the encouraging and positive comments from their support networks. Interestingly, as they became more confident in themselves, they started to be less competitive with others. Instead, they focused more on developing themselves. As Cindy put it, “I don't want to compare with others anymore [...] and I don't need to, which means that I'm becoming more confident [...] I think I'm becoming a different person. And I'm happy." Another participant, Kim, also thought that the university had "a warmer environment." She shared, "I guess I fall in love with [State name]. I really love it. And so, again, I like everything I guess.” Her experience at the university has been a very positive one:

It was a positive experience for me, and from, you know, my interactions with other people and other graduate students, I didn't hear anybody complaining or anything, so...it's a good place. I didn't hear negative things from other students in other departments, so, I think the university is just, you know, having a good support system and services. That was my experience.

Another important reason for the participants' positive perception of their new environment was different gender expectations. Most of them thought that U.S. society affords women much more freedom and intellectual respect. One participant, Beth, specifically elaborated on how the career opportunities for women were so much better in the U.S.:

The situation here is that the women don't face as many problems [as] we have in our country. Um, actually I think the number of women to get accepted for jobs with PhD's is actually higher for women than men here or very close. So I feel there is good opportunity for women in the US.

A combination of a warm atmosphere, friendly local people, encouraging comments, and more progressive social norms helped the participants in this study form a sense of belonging to a place so strange and so far from home. They found ways to not just adjust to, but to thrive in, the new environment.

\section{Appreciation/Gratitude}

All of the participants shared a deep sense of appreciation for the opportunity to come to study in the U.S. and for all of the people who helped them along the way. For most of them, this was a dream come true. They did not grow up in extremely affluent families where going to study 
abroad is just a fact of life. These students came from middle class families with limited exposure to resources that would help them prepare for going abroad. For all of them, having a graduate assistantship was the only way they could afford the tuition and living costs at a U.S. university. Additionally, being females in more traditional societies, they had not been encouraged to pursue education so far away from home. Yet, against all odds, they were able to come to the U.S. and were making great progress in their personal, social, and academic lives. While acknowledging their own personal efforts to get to where they were in life, they also emphasized how they appreciated others who had helped them along the way, as Jane reflected:

Of course that took a lot of effort not only on my part but on everybody else who was involved in the process as my friends and my family and educators and administrators all over, you know, between the two continents. They were putting things together to help me achieve where I am now.

Though she has been in the U.S. for years, she could hardly believe that it was real:

It was very surreal. I have to remind myself that this is actually going on. So it's really I was glad and maybe that's part of my personality too. I am grateful for the little thing and I am super grateful for the big thing in my life. I don't let anything pass by without being acknowledged how great it is, you know, how few people get a chance like that.

More specifically, most of them credited their professors/advisors for being supportive and inspiring. They appreciated the professors' efforts to help them feel valued in the classrooms. Being the only or one of the few international students in their programs, some participants initially felt left out of the course discussions. They felt fortunate to have professors who were intentional and consistent in creating an inclusive learning environment for international students. Cindy shared:

But the good thing is, you know, some professors are very good in terms of involving all the students. They would say, oh, for example, "[INTERVIEWEE NAME REDACTED] what do you think in your country? What do you think in your experience? What would you think in the industry, in the company?” Some professors 
are very good in terms of involving you, so you don’t feel being left out.

Some of them are grateful for the chance to learn from great professors who were experts in their fields and who inspired their students to develop their professional interests. The participants shared that these great professors not only inspired them academically but also personally to become more critical thinkers and more open-minded. Kim expressed:

I think I was also fortunate to learn from so many great professors, that were really sharing their knowledge with us, and I was able to see things differently. I think it makes you a different person. When you have opportunities to go abroad and study abroad. Since I live in two different cultures, I think I'm, like, more open now to everything, and I think it's a great opportunity.

For some participants, the opportunity to have their preconceived notions of the U.S. challenged was a great learning experience that had profound effects on their world view. Especially for those growing up in societies with anti-American attitudes, they were appreciative of the chance to get to know Americans on a personal level as real humans, not just as part of a propaganda. They were grateful that their minds were changed for the better. Beth elaborated that friendliness and the character of the people have really made this experience pleasant for her:

You know because of some stereotypes and propaganda about the US in my country, I never thought that the people of America would be so kind and helpful. I found them very different than what my country tries to make. It was surprising for me that they are so polite, so kind, so helpful, and so generous. I am very happy to study here. I feel peaceful. I feel happy. I am glad to have this experience.

On a more practical side, the participants expressed gratitude for the financial and professional development support afforded to them through their graduate assistantships. Annie indicated that her assistantship's tuition remission was "very important" to her and that this experience made her feel "well prepared to succeed and work in" her field of study. Sam concurred that being able to get a scholarship as a research assistant "was the most important part" of her opportunity, as she would not have been able to afford tuition and the cost of living otherwise. Additionally, she explained that because of her positive experience with the culture and academic 
opportunity she "want[s] to stay here and work," whereas she never would have considered living and working so far from home an option before.

\section{Structural Description: Factors That Contribute to the Experience}

The experience of being an international female graduate student is framed by a sense of balancing many roles and cultures at once. The transitioning period from home countries to host countries is characterized by a mixed feeling of excitement and anxiety. The participants initially experienced a shock when transitioning from their native cultures to the U.S. However, this challenging period also provided great opportunities for growth as the participants reached out to people around them for support. Being graduate students, most of their time was spent within their academic departments, especially with their advisors, so they invested a lot of time and energy in creating and maintaining good relationships with their professors and advisors. The participants have successfully established positive relationships with their professors and friends. These relationships contribute significantly to the participants' personal growth. Their selfimage has changed for the better. Having to overcome so many obstacles made them appreciate the opportunity more (simply obtaining a visa to come to the U.S. can, in itself, be quite an ordeal). Also, they have experienced two different cultures and were able to pick and choose what works best for them. Being in the U.S. also freed them from many traditions and customs that do not fit with their preferred lifestyles. They feel free to re-invent their identities without the strict influence of their home society.

The participants were from families of moderate means. They were exposed to and encouraged to attend higher education since childhood, but going to the U.S. to study is still a fantasy come true. Thus, they work hard to make the most out of this opportunity. They develop a new set of skills to help them thrive in the new environment. Successfully acquiring these new skills and relationships has a significant influence on how the participants view other experiences in their lives.

\section{Composite Description: The Essence of the International Female Graduate Student Experience}

Each of the participants has a unique background and is in a different life stage. Thus, they have different concerns. However, they all share a positive perception of their experience as an international female graduate student at a Midwestern university in the U.S. They are all trying their best to make the best of their situations. They have turned initial difficulties into motivation to try harder. There is a sense of transformation, a chance to start fresh. They are nervous but excited to discover new qualities they did not know existed inside them. They keep reframing their 
experiences into a positive perspective to help them learn new lessons. They felt great gratitude for the people who have helped them academically and socially. They did not take things for granted. While acknowledging that they work hard, they also attributed their success to the support from their professors, advisors, and friends.

\section{DISCUSSION}

\section{Implications for Practice}

Based on the findings from this study, there are several implications for educators and administrators who seek to better assist international female graduate students in their academic and social adjustment process. First, as all participants emphasized, their relationship with an advisor/mentor was vital to their adjustment process and sense of belonging. The advisors/mentors were perceived as their main support in academic and personal issues. Hence, universities and academic departments should invest in training for faculty in working with international students. Many faculty have already tried their best to support their international advisees. However, providing faculty with more formal training on major issues regarding international students might make the advising relationship more productive and effective for both the faculty and the advisees.

Another area for consideration is programming for events and groups targeting international female graduate students. All of the participants shared that they barely ever used any of the university student services or attended any student events. There seems to be a disconnection with the institution as a whole. Rather, they usually sought help from their personal support network, such as friends, spouses, and host families. Universities and academic departments with a considerable number of international female graduate students could be more proactive in providing support for this student population by creating extended orientation programs addressing common concerns and by setting up formal support networks, such as peer mentoring, and monthly social events.

Additionally, universities with a substantial number of international female graduate students should invest in more programs/services that provide assistance with visa and immigration issues. Five out of the seven participants cited considerable stress, anxiety, and difficulty with their immigration status. This reinforces how essential immigration specialists and related services are on a university campus. Another point of concern is that international female graduate students might have uncommon stressorssuch as pregnancy, giving birth, and caring for small children-which might affect their academic progress and ability to secure employment right after graduation. 


\section{RECOMMENDATIONS FOR FUTURE RESEARCH}

We concluded that the ability to positively reframe experiences or make positive meanings for experiences plays an essential role in the participants' capacity to adjust to and thrive in their new environment. The findings also show that all of the participants in this study perceived their experience as a mostly positive transformation in which they developed personally and socially. This sentiment contradicts the popular deficit model of international students as a vulnerable and disfranchised group. This deficit model fails to capture the complexity and diversity in these students' development and overlooks how the acculturation process can promote resiliency, growth, learning, and positive self-development (Chirkov, 2009). Thus, future research should aim to explore the complex and contextualized experiences of international students and the transformative potential of the study abroad experience.

Additionally, the findings from this study also suggest that the participants employ a complex and intentional approach to social network building. They understand the importance of being exposed to diverse ideas and people. Some of their relationships are functional (as with university staff), some are personal (as with their close friends), and some are both (as with their advisors). This finding is congruent with recent studies on international students' networking/friendship patterns (Montgomery, 2010; Pham \& Saltmarsh, 2013). For future research on this particular topic, researchers should be mindful of the multifaceted and strategic nature of international students' social network selection.

Finally, we recommend that future research employ various data collection methods, such as longitudinal interviews and factor analysis, to contribute to a holistic understanding of this student population. For example, factor analysis techniques could be used to examine the relationship between international female graduate students' perception of the campus environment and their academic progress and retention rates, and longitudinal study could best elaborate a description of how international students develop over the course of their college years.

This study had a few limitations. First, the sample was small and limited to one institution. Future research on this student population should include more participants and more institutions to increase the generalizability of findings. Second, the data collected in this qualitative study were based in part on self-reflection and recollection of past events. Perceptions of these events might have changed over time or details might have been left out. 


\section{REFERENCES}

Arkoudis, S. (2006). Teaching international students: Strategies to enhance learning. Victoria,

Australia: Centre for the Study of Higher Education (Melbourne).

Retrieved from

http://www.cshe.unimelb.edu.au/pdfs/international.pdf

Baird, L. (1990). The melancholy of anatomy: The personal and professional development of graduate and professional school students. In J.C. Smart (Ed.) Higher education: Handbook on Theory and Research. Vol. 6. New York: Agathon Press.

Bektas, Y., Demir, A., \& Bowden, R. (2009). Psychological adaptation of Turkish students at U.S. campuses. International Journal for the Advancement of Counselling, 31(2), 130-143.

Bhabha, H. (1994). The location of Culture. London, UK: Routledge.

Bochner, S., McLeod, B., \&Lin, A. (1977). The friendship patterns of overseas and host students in an Oxford student residence. Journal of Social Psychology, 125 (6), 689-694.

Bogdan, R. C. \& Biklen, S. K. (1992). Qualitative research for education. Boston: Allyn and Bacon.

Bradley, G. (2000). Responding effectively to the mental health needs of international students. Higher Education, 39(4), 417-433.

Brown, L., \& Holloway, I. (2008). The adjustment journey of international postgraduate students at an English university: An ethnographic study. Journal of Research in International Education, 7(2), 232249.

Campbell, J., \& Li, M. (2008). Asian students' voices: An empirical study of Asian students' learning experiences at a New Zealand university. Journal of Studies in International Education, 12(4), 375-396.

Chirkov, V. (2009). Summary of the criticism and of the potential ways to improve acculturation psychology. International Journal of Intercultural Relations. 33 (2), 177-180.

Creswell, J. W. (2012). Qualitative inquiry and research design: Choosing among five approaches. Thousand Oaks, CA: Sage.

Deakins, E. (2009). Helping students value cultural diversity through research-based teaching. Higher Education Research \& Development, 28(2), 209-226.

Ellis, B., Sawyer, J., Gill, R., Medlin, J., \& Wilson, D. (2005). Influences of the learning environment of a regional university campus on its international graduates. Australian Educational Researcher, 32(2), 65-85. 
Hanassab, S. (2006). Diversity, international students, and perceived discrimination: Implications for educators and counselors. Journal of Studies in International Education, 10(2), 157-172.

Hawkins, M. R. (2005). Becoming a Student: Identity work and Academic Literacies in Early Schooling. TESOL Quarterly, 39 (1),: 59-82.

Hsieh, M. H. (2006). Identity negotiation among female Chinese international students in second-language higher education. College Student Journal, 40(4), 870-885.

Institute of International Education (IIE). (2015). Special Reports: Economic Impact of International Students. Retrieved from http://www.iie.org/Research-and-Publications/Open-

Doors/Data/Economic-Impact-of-International-Students.

Klomegah, R. Y. (2006). Social factors relating to alienation experienced by international students in the United States. College Student Journal, 40(2), 303-315.

Knefelkamp, L. L. (1999). Introduction. In W. G. Perry, Jr., Forms of ethical and intellectual development in the college years: A scheme (pp. xi-xxxvii). San Francisco, CA: Joseey-Bass.

Kramsch, C. (1993). Context and culture in Language Teaching. Oxford, UK: Oxford University Press

Labi, A., Birchard, K., \& Overland, M. A. (2008). As world economies struggle, competition heats up for students from abroad. Chronicle of Higher Education, 55(13), A22-A22.

Leask, B. (2009). Using formal and informal curricula to improve interactions between home and international students. Journal of Studies in International Education, 13(2), 205-221

Lee, J. J. (2007). Neo-racism toward international students. About Campus, 11(6), 28-30.

Lee, J. J. (2008). Beyond borders: International student pathways to the United States. Journal of Studies in International Education, 12(3), 308-327.

Lee, J. J., \& Rice, C. (2007). Welcome to America? International student perceptions of discrimination. Higher Education: The International Journal of Higher Education and Educational Planning, 53(3), 381409.

Lester, S. (1999). An introduction to phenomenological research. Taunton, UK: Stan Lester Developments. Retrieved from www.sld.demon.co.uk/resmethy.pdf

Li, H., Fox, R. F., \& Almarza, D. J. (2007). Strangers in stranger lands: Language, learning, culture. International Journal of Progressive Education, 3(1), 6-28. 
Lin, S. Y., \& Scherz, S. D. (2014). Challenges Facing Asian International Graduate Students in the US: Pedagogical Considerations in Higher Education. Journal of International Students, 4(1), 16-33.

Mallinckrodt, B.\& Leong, F.T.L. (1992). Social support in academic programs and family environments: Sex differences and role conflicts for graduate students. Journal of Counseling and Development. Vol. 70, no. 4, pp. 716-723

Manese, J. E., Sedlacek, W. E., \& Leong, F. T. (1984). Needs and perceptions of female and male international undergraduate students. College Park, Md.: Counseling Center, University of Maryland.

McClure, J. W. (2007). International graduates' cross-cultural adjustment: Experiences, coping strategies, and suggested programmatic responses. Teaching in Higher Education, 12(2), 199-217.

McLachlan, D. A., \& Justice, J. (2009). A grounded theory of international student well-being. Journal of Theory Construction \& Testing, 13(1), 27-32.

McMillen, P. J. (1982). Problems of international students at the George Washington University Dissertation Abstracts International, 42(07), 3018A.

Mitchell, S. L., Greenwood, A. K., \& Guglielmi, M. C. (2007). Utilization of counseling services: Comparing international and U.S. college students. Journal of College Counseling, 10(2), 117.

Montgomery, C. (2010). Understanding the international student experience. New York, NY: Palgrave Macmillan.

Pham, L., \& Saltmarsh, D. (2013). International students' identities in a globalized world: Narratives from Vietnam. Journal of Research in International Education, 12 (2),: 129-14.

Pollock, D.C., \& Van Reken, R.E. (1999) The third culture kid experience: Growing up among worlds. Yarmouth, ME: Intercultural Press.

Pruitt, F. J. (1978). The adaptation of foreign students on American campuses. Journal of the NAWDAC, 41(4), 144-149.

Robinson-Pant, A. (2009). Changing academies: Exploring international PhD students' perspectives on 'host' and 'home' universities. Higher Education Research \& Development, 28(4), 417-429.

Sam, D. (2001). Satisfaction with life among international students: An exploratory study. Social Indicators Research, 53(3), 315-337.

Sawir, E., Marginson, S., Deumert, A., Nyland, C., \& Ramia, G. (2008). Loneliness and international students: An Australian study. Journal of Studies in International Education, 12(2), 148-180. 
Searle, W., \& Ward, C. (1990). The prediction of psychological and sociocultural adjustment during cross-cultural transitions. International Journal of Intercultural Relations, 14(4), 449-464.

Smith, J. A., Flowers, P., \& Larkin, M. (2009). Interpretative phenomenological analysis: Theory, method and research. Qualitative Research in Education, 6 (4), 346-347.

Urias, D., \& Yeakey, C. C. (2009). Analysis of the U.S. student visa system: Misperceptions, barriers, and consequences. Journal of Studies in International Education, 13(1), 72-109.

Vertovec, S. (1999). Three meanings of 'diaspora', exemplified among South Asian religions. Diaspora, 6 (3), 277-299.

Wang, J. (2009). A study of resiliency characteristics in the adjustment of international graduate students at American universities. Journal of Studies in International Education, 13(1), 22-45.

Ward, C., \& Kennedy, A. (1993). Psychological and socio-cultural adjustment during cross-cultural transitions: a comparison of secondary students overseas and at home. International Journal of Psychology, 28 (2), 129-147.

Yoh, T., Yang, H., \& Gordon, B. (2008). Status of participation in physical activity among international students attending colleges and universities in the United States. College Student Journal, 42(4), 1110-1117.

Zhao, C., Kuh, G. D., \& Carini, R. M. (2005). A comparison of international student and American student engagement in effective educational practices. The Journal of Higher Education, 76(2), 209-231.

ANH T. LE, PhD, is currently an academic advisor/success coach for international students at the University of Nebraska-Lincoln (UNL). Her research focuses on factors contributing to international students' success and identity development in undergraduate and graduate education in the United States. Email: ale10@unl.edu

BARBARA Y. LACOST, PhD, is an associate professor in Educational Administration at the University of Nebraska-Lincoln. She has more than four decades of experience in the field of educational administration. She holds a doctorate from Louisiana State University. She has written several monographs and articles on educational administration, educational budgeting, and women in educational leadership. Email: blacost1@unl.edu

MICHAEL WISMER, MA, holds a master's degree in Educational Administration from the University of Nebraska-Lincoln. He is currently the Coordinator of Orientation Activities in the New Student Enrollment office at UNL. Email: mwismer2@unl.edu

$\frac{1 * * *}{152}$

